\title{
The serum level of anti-phospholipase A2 receptor antibody does not predict severity of proteinuria in primary membranous glomerulonephritis
}

\author{
Sepideh Hajian $^{1}$, Ali Sarbazi-Golezari ${ }^{2,3}$, Nazanin Samandari ${ }^{3^{*}}$ \\ ${ }^{1}$ Department of Nephrology, Velayat Hospital, Qazvin University of Medical Sciences, Qazvin, Iran \\ ${ }^{2}$ Student Research Committee, Qazvin University of Medical Sciences, Qazvin, Iran \\ ${ }^{3}$ Metabolic Diseases Research Center, Research Institute for prevention of Non- Communicable Disease, Qazvin University of Medical \\ Sciences, Qazvin, Iran
}

\section{A R T I C L E IN F O}

\section{Article Type:}

Original

\section{Article History:}

Received: 22 November 2020

Accepted: 13 December 2020

Published online: 7 January 2021

\section{Keywords:}

Primary membranous glomerulonephritis, Antiphospholipase A2 receptor antibody, Diagnosis, Prognosis, Proteinuria

\begin{abstract}
A B S T R A C T
Introduction: Anti-phospholipase A2 receptor (anti-PLA2r) antibody is a marker in blood and has been recently reported that it is increased in patients with primary membranous glomerulonephritis (MGN).

Objectives: To investigate the role of this receptor in severity of proteinuria in primary MGN, we evaluated the relationship between serum level of this receptor and proteinuria in patients with primary MGN.

Patients and Methods: This study was conducted on patients with primary MGN referring to the nephrology clinic in Qazvin province during 2016-2017. Serum level of anti-PLA2r and level of proteinuria before and after medical treatments were measured. Anti-PLA2r was measured using the enzyme-linked immunosorbent assay (ELISA) kits.

Results: Anti-PLA2r was positive and negative in $42.3 \%$ and $57.7 \%$ of the patients with primary MGN, respectively. There was no significant relationship between serum level of anti-PLA2r and level of proteinuria before and after the medical treatments.

Conclusion: Our data show that anti-PLA2r could not predict the severity of proteinuria in patients with primary MGN.
\end{abstract}

Implication for health policy/practice/research/medical education:

In a study on 28 patients with primary membranous glomerulonephropathy, we found no significant relationship between anti phospholipase A2 receptor antibody and level of proteinuria.

Please cite this paper as: Hajian S, Sarbazi-Golezari A, Samandari N. The serum level of anti-phospholipase A2 receptor antibody does not predict severity of proteinuria in primary membranous glomerulonephritis. J Renal Inj Prev. 2021; 10 (2): e15. doi: 10.34172/jrip.2021.15.

\section{Introduction}

Membranous glomerulonephritis (MGN) is a progressive autoimmune chronic kidney disease (1) that may result in nephritic syndrome, renal failure, and increased mortality rate $(1,2)$. It includes two main types including primary type in $70 \%-80 \%$ and secondary type in $20 \%-30 \%$ (1). For definite diagnosis of the primary type of MGN, secondary causes including neoplasms must be ruled out $(1,2)$. However, these diagnostic methods are time-consuming, expensive and also occasionally invasive modalities (2). Anti-phospholipase A2 receptor (anti-PLA2r) antibody $\mathrm{Ab}$ can help to distinction between these two types that is useful in decision-making for treatment in patients (2). Detection of anti-PLA2r is a simple non-expensive method to distinguish between primary and secondary types of MGN and it also may be used for therapeutic response monitoring $(1,2)$. PLA2r is a membranous glycoprotein on podocytes and type $M$ is affected as the main antigen in autoimmune processes $(2,3)$. The antigen-antibody complexes are precipitated in basement membrane leading to production of excess amount of collagen and laminine that activates complement activation resulting in proteinuria (3). Anti-PLA2r is a sensitive marker for disease activity since low-titers show lower risk of renal 
failure and higher chance for spontaneous remission (3). Increased antibody titer is seen before proteinuria and it can be measured as an early marker (3).

\section{Objectives}

This study was performed to evaluate the anti-PLA2r as a prognostic factor in primary MGN.

\section{Patients and Methods}

Study design

This cross-sectional descriptive comparative study was conducted on all patients with primary MGN referring to the nephrology clinic in Qazvin province during 20162017.

The sampling was non-randomized and consecutive. Inclusion criterion was patients with established primary MGN. Definite diagnosis of primary MGN was conducted by a blind pathologist. Exclusion criterion was patients with secondary MGN.

Data were collected by questionnaire and measuring the serum level of anti-PLA2r. The patients were also sorted into three different groups according to their kind of treatments. These three kinds of treatment are; calcineurin inhibitors (CNIs)+ corticosteroids, cyclopho sphamide+corticosteroids and rituximab+corticosteroids.

The blood samples were taken from the patients with primary MGN. Then these samples were centrifuged and the supernatant serums were divided and stored at $-80^{\circ} \mathrm{C}$ until measurement.

Serum level of anti-PLA2r of the patients was measured by using ELISA (IFA, Euroimmun AG, Luebeck, Germany) kit according to manufacturer's instructions. Serum level of greater than $20 \mathrm{RU} / \mathrm{mL}$ was considered positive.

Amount of proteinuria before and after the treatments were collected. According to these data the partial remission was considered more than 50\% decrease in amount of proteinuria before the treatment.

\section{Ethical issues}

The research followed the tenets of the Declaration of Helsinki. The Ethics Committee of Qazvin University of Medical Sciences approved this study. The institutional ethical committee at Qazvin University of Medical Sciences approved all study protocols (IR.QUMS.REC.1395.322). Accordingly, written informed consent was taken from all participants before any intervention. The information contained in this article was extracted from a M.D thesis by Nazanin Samandari at Qazvin University of Medical Sciences.

\section{Data analysis}

SPSS 20 software was used for data analysis. Qualitative variables were described using frequency and percentage and quantitative variables were presented using means. Oneway ANOVA test were used for data analysis. $P<0.05$ was set as the level of significance.

Results

Twenty-eight patients with primary MGN were diagnosed and enrolled during the study period. There were $19(67.9 \%)$ male patients. Fifteen patients received CNIs + corticosteroids, seven patients received cyclophosphamide + corticosteroids and six patients received rituximab+corticosteroids.

The mean of age patients was 31.32 years old and the average of duration of disease after diagnosis was 4.71 month. The mean of disease onset age was 30.92 years old. Table 1 shows the demographical characteristics of the patients according to their gender.

There was no significant correlation between serum level of anti-PLA2r and amount of proteinuria before the treatment $(P=0.81)$ and after treatment $(P=0.737)$ in male patients with primary MGN. Additionaly, there was no significant correlation between amount of proteinuria $(P=0.935)$ before the treatment and after the treatment $(P=0.458)$ in female patients.

There was no significant correlation between serum level of anti-PLA2r in patients with primary MGN according to their kind of treatment and the amount of proteinuria after the treatment. The $P$ values in the groups receiving treatment with CNIs + corticosteroids, cyclophosphamide + corticosteroids and rituximab+ corticosteroids were $0.711,0.121$ and 0.310 , respectively and the mean of serum level of anti-PLA2r were 78.74, 80.62 and 129.65 , respectively.

There was no significant correlation between serum level of anti-PLA2r and remission rate in patients treated with first line $(P=0.251)$, second line $(P=0.221)$ and third line drugs $(P=0.917)$.

\section{Discussion}

In this study, the serum level of anti-PLA2r did not correlate with clinical characteristics of patients such as proteinuria.

In our study, anti-PLA2r Ab test did not significantly correlate with amount of proteinuria. In a study that was conducted on forty-eight patients with primary MGN, proteinuria was more severe in anti-PLA2r positive patients than in anti-PLA2r-negative patients. In addition, it showed that anti-PLA2 $\mathrm{r}$ Ab level was positively correlated with proteinuria (4).

In another study that was carried out on 75 patients with

Table 1. Demographic characteristics of patients

\begin{tabular}{lcc}
\hline Gender & Male $(\mathbf{n = 9})$ & Female $(\mathbf{n = 1 9 )}$ \\
\hline Mean of age (years) & 29.44 & 32.21 \\
$\begin{array}{l}\text { Duration of disease after diagnosis } \\
\text { (month) }\end{array}$ & 4.22 & 4.94 \\
Disease onset age (years) & 29.09 & 31.79 \\
\hline
\end{tabular}


biopsy proven MGN, 45 out of 60 patients with primary MGN, the test anti PLA2r Ab was positive. They showed that there was a significant correlation with quantity of proteinuria and negative correlation with serum albumin (5).

In a study that was done on 90 patients with biopsy proven primary MGN, anti PLA2r was positive in three quarters of patients. They showed that there was significant link between anti-PLA2r antibody and outcome (6).

However, in a study that retrospectively screened all adult patients with biopsy-proven primary MGN diagnosed between 1978 and 2007, showed that there was no significant association between anti-PLA2r Ab titer at diagnosis with baseline proteinuria in agreement with our data (7).

Several other studies showed that anti-PLA2r $\mathrm{Ab}$ are associated with disease activity and remission (6,811). However, some others reported conflicting results $(7,12-14)$.

The different data are maybe because of failure of antiPLA2r Ab to reflect the clinincal activity of membranous nephropathy accurately when amount of proteinuria was evaluated.

\section{Conclusion}

Totally, it is concluded that anti-PLA2 $\mathrm{r} A b$ is not an appropriate tool to predict the amount of proteinuria in patients with primary MGN. However further studies with larger sample size are required to attain more definite results about distinctive role of anti-PLA2r Ab.

\section{Limitations of the study}

This study was conducted on a limited number of patients. Further investigation on this subject as a multi-cantric with larger population are necessary.

\section{Authors' contribution}

$\mathrm{SH}, \mathrm{AS}$ and NS were the principal investigators of the study. SH and NS were included in preparing the concept and design. All authors participated in preparing the final draft of the manuscript, revised the manuscript and critically evaluated the intellectual contents. All authors have read and approved the content of the manuscript and confirmed the accuracy or integrity of any part of the work.

\section{Conflicts of interest}

The authors declared no conflict of interest with regards to the research, authorship, and/or publication of this article.

\section{Ethical considerations}

Ethical issues (including plagiarism, data fabrication, double publication) have been completely observed by the authors.

\section{Funding/Support}

The authors declared no receipt of the following financial support for the research, authorship, and/or publication of this article.

\section{References}

1. Horvatic I, Galesic K. Membranous glomerulonephritisrecent advancesin pathogenesis and treatment. Lijec Vjesn. 2012;134:328-39.

2. Cybulsky AV. Membranous nephropathy. Contrib Nephrol. 2011;169:107-25.

3. Ronco P, Debiec $H$. Antigen identification in membranous nephropathymoves toward targeted monitoring and new therapy. J Am Soc Nephrol. 2010;21:564-9.

4. Song EJ, Jeong KH, Yang YA, Lim JH, Jung HY, Choi JY, et al. Anti-phospholipase A2 receptor antibody as a prognostic marker in patients with primary membranous nephropathy. Kidney Res Clin Pract. 2018;37:248-56. doi: $10.23876 /$ j.krcp.2018.37.3.248.

5. Gopalakrishnan N, Abeesh P, Dineshkumar T, Murugananth S, Sakthirajan R, Raman GS, et al. Prevalence of serum anti M-type phospholipase A2 receptor antibody in primary membranous nephropathy: A single center experience. Indian J Nephrol. 2016;26:257-61. doi: 10.4103/0971-4065.160334.

6. Kanigicherla D, Gummadova J, McKenzie EA, Roberts SA, Harris S, Nikam M, et al. Anti-PLA2R antibodies measured by ELISA predict long-term outcome in a prevalent population of patients with idiopathic membranous nephropathy. Kidney Int. 2013;83:940-8. doi: $10.1038 / \mathrm{ki} .2012 .486$.

7. Jullien P, Seitz Polski B, Maillard N, Thibaudin D, Laurent B, Ollier E, et al. Anti-phospholipase A2 receptor antibody levels at diagnosis predicts spontaneous remission of idiopathic membranous nephropathy. Clin Kidney J. 2017;10:209-14. doi: 10.1093/ckj/sfw121.

8. Hoxha E, Thiele I, Zahner G, Panzer U, Harendza S, Stahl RA. Phospholipase A2 receptor autoantibodies and clinical outcome in patients with primary membranous nephropathy. J Am Soc Nephrol. 2014;25:1357-66.

9. Kim YG, Choi YW, Kim SY, Moon JY, Ihm CG, Lee TW, et al. Anti-phospholipase A2 receptor antibody as prognostic indicator in idiopathic membranous nephropathy. Am J Nephrol. 2015;42:250-7. doi: 10.1159/000440983.

10. Timmermans SA, Abdul Hamid MA, Cohen Tervaert JW, Damoiseaux JG, van Paassen P; Limburg Renal Registry. Anti-PLA2R antibodies as a prognostic factor in PLA2R-related membranous nephropathy. Am J Nephrol. 2015;42:70-7. doi: 10.1159/000437236.

11. Wei SY, Wang YX, Li JS, Zhao SL, Diao TT, Wang Y, et al. Serum anti-PLA2R antibody predicts treatment outcome in idiopathic membranous nephropathy. Am J Nephrol. 2016;43:129-40. doi: 10.1159/000445361.

12. Hoxha E, Kneißler U, Stege G, Zahner G, Thiele I, Panzer U, et al. Enhanced expression of the M-type phospholipase A2 receptor in glomeruli correlates with serum receptor antibodies in primary membranous 
nephropathy. Kidney Int. 2012;82:797-804. doi: 10.1038/ ki.2012.209.

13. Hofstra JM, Debiec H, Short CD, Pellé T, Kleta R, Mathieson PW, et al. Antiphospholipase A2 receptor antibody titer and subclass in idiopathic membranous nephropathy. J Am Soc Nephrol. 2012;23:1735-43. doi: 10.1681/ASN.2012030242.
14. Pourcine F, Dahan K, Mihout F, Cachanado M, Brocheriou I, Debiec H, et al. Prognostic value of PLA2R autoimmunity detected by measurement of anti-PLA2R antibodies combined with detection of PLA2R antigen in membranous nephropathy: a single-centre study over 14 years. PLoS One. 2017;12:e173201. doi: 10.1371/ journal.pone. 0173201 .

Copyright (c) 2021 The Author(s); Published by Nickan Research Institute. This is an open-access article distributed under the terms of the Creative Commons Attribution License (http://creativecommons.org/licenses/by/4.0), which permits unrestricted use, distribution, and reproduction in any medium, provided the original work is properly cited. 